Flammability and Sensitivity of Materials in Oxygen-Enriched Atmospheres

PAPER ID: STP-2015-0087

Available online at www.astm.org

Susana A. Harper ${ }^{1}$, Alfredo Juarez ${ }^{2}$, Stephen F. Peralta ${ }^{3}$, Joel Stoltzfus ${ }^{4}$, Christina Piña Arpin ${ }^{5}$, Harold D. Beeson, Ph.D. ${ }^{6}$

\title{
An Improved Approach for Analyzing the Oxygen Compatibility of Solvents and other Oxygen-Flammable Materials for Use in Oxygen Systems
}

\author{
REFERENCE: Harper, S.A. Juarez, A., Peralta, S.F., Stoltzfus, J.M., Piña Arpin, C.Y., and \\ Beeson, H.D., “An Improved Approach for Analyzing the Oxygen Compatibility of Solvents and \\ other Oxygen-Flammable Materials for Use in Oxygen Systems,” Fourteenth International \\ Symposium on Flammability and Sensitivity of Materials in Oxygen-Enriched Atmospheres, \\ STP 1596, E. Davis and T.A. Steinberg, Editors, STP-2015-0087, ASTM International, West \\ Conshohocken, PA. 2016.
}

\begin{abstract}
Solvents used to clean oxygen system components must be assessed for oxygen compatibility, as incompatible residue or fluid inadvertently left behind within an oxygen system can pose a flammability risk. The most recent approach focused on solvent ignition susceptibility to assess the flammability risk associated with these materials. Previous evaluations included Ambient Pressure Liquid Oxygen (LOX) Mechanical Impact Testing (ASTM G86) and Autogenous Ignition Temperature (AIT) Testing (ASTM G72). The goal in this approach was to identify a solvent material that was not flammable in oxygen. As environmental policies restrict
\end{abstract}

\footnotetext{
1 Standard Test Project Manager, Materials and Component Laboratories Office, NASA White Sands Test Facility, Las Cruces, New Mexico.

2 Standard Test Lead Flammability Test Engineer, NASA Test and Evaluation Contract, NASA White Sands Test Facility, Las Cruces, New Mexico.

3 Flammability Project Manager, Lockheed Martin, NASA Johnson Space Center, Houston, Texas.

4 Standard Test Flammability Consultant, NASA White Sands Test Facility, Las Cruces, New Mexico.

5 Component Services Project Manager, NASA White Sands Test Facility, Las Cruces, New Mexico.

6 Materials and Component Testing Laboratories Office Chief, NASA White Sands Test Facility, Las Cruces, New Mexico.
} 
the available options of acceptable solvents, it has proven difficult to identify one that is not flammable in oxygen. A more rigorous oxygen compatibility approach is needed in an effort to select a new solvent for NASA applications. NASA White Sands Test Facility proposed an approach that acknowledges oxygen flammability, yet selects solvent materials based on their relative oxygen compatibility ranking, similar to that described in ASTM G63-99. Solvents are selected based on their ranking with respect to minimal ignition susceptibility, damage and propagation potential, as well as their relative ranking when compared with other solvent materials that are successfully used in oxygen systems. Test methods used in this approach included ASTM G86 (Ambient Pressure LOX Mechanical Impact Testing and Pressurized Gaseous Oxygen (GOX) Mechanical Impact Testing), ASTM G72 (AIT Testing), and ASTM D240 (Heat of Combustion (HOC) Testing). Only four solvents were tested through the full battery of tests for evaluation of oxygen compatibility: AK-225G as a baseline comparison, Solstice PF, L-14780, and Vertrel MCA. Baseline solvent AK-225G exhibited the lowest HOC and highest AIT of solvents tested. Nonetheless, Solstice PF, L-14780, and Vertrel MCA HOCs all fell well within the range of properties that are associated with proven oxygen system materials. Tested AITs for these solvents fell only slightly lower than the AIT for the proven AK-225G solvent. Based on these comparisons in which solvents exhibited properties within those ranges seen with proven oxygen system materials, it is believed that Solstice PF, L-14780, and Vertrel MCA would perform well with respect to oxygen compatibility.

Keywords: materials selection, oxygen compatibility, oxygen flammability, solvent, cleaning solvent, gaseous oxygen, G86, G72, G63, D240 


\section{Background}

Asahi AK-225G ${ }^{\circledR 7}$ was selected in 2001 as a replacement solvent for cleaning oxygen system components after the 1987 Montreal Protocol on Substances that Deplete the Ozone Layer required the reduction and eventual phase-out of chlorofluorocarbons, which included the widely used cleaning solvent CFC-113. With regard to oxygen compatibility, AK-225G has been a preferred solvent for its perceived nonreactivity in the tests used to evaluate potential solvents at the time of selection [1]. AK-225G has been used successfully and without incident for over a decade. As environmental policies continue to phase out available solvent options, a NASA multicenter initiative has sought to identify and select a long-term replacement solvent. Because solvents are used to clean oxygen system components, oxygen compatibility is one of the key areas evaluated as part of solvent selection criteria, in addition to various other areas including metals compatibility, nonmetals compatibility, cleaning effectiveness, nonvolatile residue, environmental regulation standing, user friendliness, and health.

Fires occur in oxygen systems when oxygen, fuel, and heat combine to create a self-sustaining chemical reaction. Fire events due to incompatibilities often result in critical loss of equipment or in catastrophic loss of life. During the 2001 investigation to replace CFC-113, a non-ignition based approach was used to select replacement solvents [1, 2]. For the current solvent investigation, the oxygen compatibility assessment approach was reevaluated. NASA White Sands Test Facility (WSTF) recommended an expanded oxygen compatibility assessment approach to allow for selection of optimal solvents.

\section{Previous Approach: Selection of Non-Ignitable Solvents}

7 AK-225G ${ }^{\circledR}$ is a registered trademark of Asahi Glass Company LTD., Tokyo, Japan. 
Historically, during the 2001 CFC-113 solvent replacement investigation, solvents were found suitable for oxygen compatibility by using a "not ignitable or flammable in oxygen” approach [1]. Flammability can be described as the characteristics of a material that pertain to its relative ease of ignition and relative ability to sustain burning using failure criteria specified in a given standard and under specified configurational and environmental conditions. Because the first step in flammability is ignition, ignition test methods were selected to evaluate the “ignitability” of the candidate solvents.

Autogenous ignition temperature (AIT) testing is a commonly used ignition test method due to its relatively good precision [3]. In the 2001 investigation, solvents were tested at low pressure (345 kPa (50 psi)) and at higher pressures (13,800 kPa (2000 psi)) to evaluate performance in various regimes. Solvents that did not ignite during standard test configurations were given preference; however, the following categories were used for evaluation of solvents that resulted in ignitions during testing (Table 1).

TABLE 1-2001 Solvent Investigation AIT Evaluation Criteria.

\begin{tabular}{lll}
\hline Category A & AIT $<121^{\circ} \mathrm{C}\left(250^{\circ} \mathrm{F}\right)$ & Not recommended for use in oxygen systems \\
Category B & $121^{\circ} \mathrm{C}<$ AIT $>204^{\circ} \mathrm{C}\left(250^{\circ} \mathrm{F}<\right.$ AIT $\left.>400^{\circ} \mathrm{F}\right)$ & Caution when used in oxygen systems \\
Category C & AIT $>204^{\circ} \mathrm{C}\left(400^{\circ} \mathrm{F}\right)$ & Recommended for use in oxygen systems \\
\hline
\end{tabular}

During the 2001 test series, seven out of the 11 solvents examined did not ignite at the low-pressure range of $345 \mathrm{kPa}$ (50 psi). Even at the high pressure of 13,800 kPa (2000 psi), three out of the 11 solvents examined did not ignite [1]. Final solvents were selected from candidates that did not ignite in AIT testing.

In addition to AIT, determining ignition sensitivity to mechanical impact in ambient liquid oxygen (LOX) (ASTM G86) was also used to evaluate ignitability of candidate solvents [4]. Despite its lower precision, LOX impact testing was one of the first oxygen ignition tests developed in the field of oxygen compatibility and provides insight into the material’s ignition sensitivity. Preference was given to solvents showing no ignitions at impacts of the highest energy levels of $97.6 \mathrm{~J}$ (72 ft-lbf). A non-ignition 
is established by obtaining zero reactions in 20 impacts or one reaction in 60 impacts. Nonetheless, any solvent passing above $27 \mathrm{~J}$ (20 ft-lbf) or showing anomalous results was still considered for further testing or evaluation. During the 2001 investigation, eight of the 11 solvents evaluated resulted in non-ignitions at $97.6 \mathrm{~J}$ (72 ft-lbf). Final solvents were selected from candidates that did not ignite in LOX impact testing.

During the 2001 investigation, the approach of selecting a solvent that could not ignite was successfully implemented. This approach was effective, as some solvents (e.g., AK-225G) showed nonignitions during both AIT and LOX impact tests. The reference solvent CFC-113 also showed nonignitions during AIT and LOX impact testing. Differentiation between solvents was made simple due to the clear distinction between reactive solvents and non-reactive solvents such as AK-225G [1]. This nonignition selection methodology is depicted as grey boxes in Fig. 1.

\section{Proposed New Approach: Application of OCA G63 /NASA STD-6001.B Concepts}

Currently, further phases of 1987 Montreal protocol implementation call for the phasing out of AK-225G, which has been the preferred solvent selected and used by NASA since the 2001 solvent investigation and selection program. Initially the 2001 oxygen compatibility evaluation approach was considered for implementation in the current NASA study; however, with further restricted options of environmentally compliant solvents available, the current investigation showed that all candidate solvents were found to ignite in oxygen-enriched environments (AIT G72, LOX Impact G86). During AIT G72 testing, method improvements were identified and led to the finding that AK-225G was in fact ignitable as well [5]. A clear distinction between acceptable and unacceptable solvents was impossible to make; therefore, a more rigorous approach was needed.

The oxygen compatibility evaluation approach was reevaluated and expanded to follow the basic principles described in ASTM G63, Standard Guide for Evaluating Nonmetallic Materials for Oxygen Service [6]. The same concepts of this methodology are in NASA STD-6001.B for analysis of oxygen 
systems [7]. Regarding the present investigation's finding that all candidate solvents were determined to be flammable, NASA STD 6001.B 6.3.2 gives the following guidance: If the materials are determined to be flammable, an oxygen compatibility assessment (OCA) shall be performed in accordance with NASA/TM-2007-213740, Guide for Oxygen Compatibility Assessments and Components and Systems [8]. The ASTM G63 Guide and NASA-STD-6001/TM-2007-213740 are systematic approaches that can be used as both a design guide and an approval process for materials, components, and systems [8].

Candidate solvents were down-selected at many points in the investigation based on not only oxygen compatibility, but also due to their performance across other selection criteria such as metals compatibility, nonmetal compatibility, cleaning effectiveness, nonvolatile residue, environmental regulation standing, user friendliness, and health. The expanded approach was used as a basis for evaluating the top candidate solvents Solstice ${ }^{\circledR 8} \mathrm{PF}$ and $3 \mathrm{M} \mathrm{L}-14780^{\circledR 9}$, as well as the reference solvent AK-225G. Vertrel ${ }^{\circledR 10}$ MCA was also reexamined, as it is currently used in certain limited applications. (At NASA the use of Vertrel MCA currently implements a secondary solvent flush due to ignitions observed during the 2001 AIT G72 testing. Information presented in this paper questions whether this secondary flush should continue to be required.) Of the 11 original solvent candidates, only these four (AK-225G as a baseline for comparison, Solstice PF, L-14780, and Vertrel MCA) were tested through the full battery of tests for evaluation of oxygen compatibility.

\section{CONCEPTUAL APPLICATION OF METHODOLOGY}

Both the ASTM G63 Guide and NASA-STD-6001/TM-2007-213740 approaches are designed to be applied to a defined system with specific operating conditions and configuration; however, the solvents in question will be used in a wide variety of systems. It would be impossible for this type of direct

8 Solstice ${ }^{\circledR}$ is a registered trademark of Honeywell International, Inc., Morristown, NJ.

$\mathrm{L}-14780^{\circledR}$ is a registered trademark of 3M Company, St. Paul, MN.

10 Vertrel $^{\circledR}$ is a registered trademark of E. I. du Pont de Nemours and Company, Wilmington, DE. 
assessment to capture every possible scenario. Nonetheless, the general concepts can be applied to generate a cohesive logic with the following fundamental evaluations:

1. Evaluation of ease of ignition

2. Evaluation of propagation and damage potential

3. Evaluation of properties affecting potential results

4. Ranking of candidate materials against each other and against historically successful oxygen-use materials for selection of an optimal solvent

A depiction of the fundamental evaluation methodology based on ASTM G63 guide and NASA-STD6001/TM-2007-213740 approaches is presented in Fig. 1 (double-lined boxes down the left-hand side of the diagram). When addressing each of these areas, it should be kept in mind that solvents will be ranked against each other and against other proven oxygen-use materials for selection. Test methods, or test method variations, should be selected that allow for performance ranking versus pass/fail results.

\section{EVALUATE EASE OF IGNITION}

Autogenous ignition temperature testing (ASTM G72) and mechanical impact testing (ASTM G86) were the test methods selected to evaluate the "ignitability" (relative ease of ignition and ability to sustain burning) of the candidate solvents.

\section{AIT ASTM G72}

The ASTM G72 AIT test method was used during the 2001 study and used again during the current study. This is a preferred method in that it provides a discrete data point versus pass/fail criteria for use in ranking of materials. In addition to the "rankability" of its data, AIT is a preferred method due to its relatively high precision [3]. To ignite any material, that material must first be heated to its AIT. The way in which this increased temperature is achieved is via a given ignition mechanism. Autogenous ignition 
temperature is an excellent general ignition assessment test method as it evaluates the end result associated with all possible ignition mechanisms. The most frequently encountered and likely to occur ignition mechanism is "Rapid Pressurization/Heat of Compression.”

During the current study, solvents were tested at two conditions: low pressure (345 kPa (50 psi)) and high pressure (13,800 kPa (2000 psi)). The high volatility of solvents complicated the ability to achieve adequate oxidizer-to-fuel ratios for testing. Sample sizes had to be increased, and testing in the $345 \mathrm{kPa}$ (50 psi) range sometimes required increased pressure to obtain valid results [5]. A pressure of $1380 \mathrm{kPa}$ (200 psi) is still a relatively low pressure and continues to accurately represent low-pressure oxygen compatibility performance. It should also be noted that the modified method led to the finding that AK-225G, previously believed to be non-ignitable, could in fact ignite [5]. This finding demonstrated the need for an elaborated oxygen compatibility evaluation methodology. All solvents evaluated were found to have an AIT at low pressures (345 to $1380 \mathrm{kPa}$ (50 to $200 \mathrm{psi})$ ) as well as at high pressures (13,800 $\mathrm{kPa}$ (2000 psi)) during the current study. These findings confirmed that all solvents are flammable and will ignite under the right circumstances. Results are presented in Table 2. 
TABLE 2-2015 Solvent Assessment Summary Data.

\begin{tabular}{|c|c|c|c|c|c|c|c|c|c|}
\hline \multirow[b]{2}{*}{ Solvent } & \multicolumn{2}{|c|}{$\begin{array}{c}\text { ASTM G86 GOX } \\
\text { Impact Pressure } \\
\text { Threshold @ 97.6 J } \\
\text { (72 ft-lbf) }\end{array}$} & $\begin{array}{c}\text { ASTM G86 } \\
\text { Ambient LOX } \\
\text { Impact Energy } \\
\text { Thresh } \\
\text { Modified Method } \\
\text { Standard Method }\end{array}$ & \multirow[t]{2}{*}{$\begin{array}{c}\text { ASTM } \\
\text { G86 } \\
\text { Past LOX } \\
\text { Impact } \\
\text { Results } \\
\text { @ 97.6 J } \\
\text { (72 ft-lbf) }\end{array}$} & $\begin{array}{c}\text { ASTM G72 } \\
\text { AIT @ 345-1379 kPa } \\
\text { (50-200 psi) } \\
\text { Modified Method } \\
\text { Standard Method }\end{array}$ & \multicolumn{2}{|c|}{$\begin{array}{c}\text { ASTM G72 } \\
\text { AIT @ 13.79 MPa } \\
\text { @2000psi } \\
\text { Modified Method } \\
\text { @2000psi } \\
\text { Standard Method } \\
\text { @1500psi }\end{array}$} & \multicolumn{2}{|c|}{$\begin{array}{c}\text { ASTM D240 } \\
\text { HOC }\end{array}$} \\
\hline & $\mathrm{MPa}$ & psi & ft-lbf & & ${ }^{\circ} \mathrm{F}(\mathrm{SD}) \quad{ }^{\circ} \mathrm{C}(\mathrm{SD})$ & ${ }^{\circ} \mathrm{F}(\mathrm{SD})$ & ${ }^{\circ} \mathrm{C}(\mathrm{SD})$ & $\mathrm{cal} / \mathrm{g}(\mathrm{SD})$ & $\mathrm{J} / \mathrm{g}(\mathrm{SD})$ \\
\hline $\begin{array}{l}\text { FlrGr } \\
\text { PTFE } \\
\text { PCTFE } \\
\text { IPA }\end{array}$ & $\begin{array}{l}30.44 \\
51.02 \\
45.61\end{array}$ & $\begin{array}{l}>4415^{\mathrm{a}} \\
7400^{\mathrm{c}} \\
6615^{\mathrm{d}}\end{array}$ & & $(1 / 60)$ & & $\begin{array}{l}479^{\mathrm{b}} \\
434^{\mathrm{b}} \\
377^{\mathrm{b}}\end{array}$ & $\begin{array}{l}248^{\mathrm{b}} \\
223^{\mathrm{b}} \\
192^{\mathrm{b}}\end{array}$ & $\begin{array}{l}2400^{\mathrm{b}} \\
1700^{\mathrm{b}} \\
2557^{\mathrm{b}} \\
7165^{\mathrm{b}}\end{array}$ & $\begin{array}{c}10,048 \\
7118 \\
10,706 \\
29,998\end{array}$ \\
\hline Solstice PF & $52^{\mathrm{e}}$ & $7500^{\mathrm{e}}$ & $\begin{array}{c}97.6^{\mathrm{e}} \\
(0 / 20)(1 / 61)\end{array}$ & & $\begin{array}{cc}464(29)^{\mathrm{e}} & 240(16)^{\mathrm{e}} \\
@ 345 \mathrm{kPa}(50 \mathrm{psi}) \\
477(13)^{\mathrm{e}} \quad 247(7)^{\mathrm{e}} \\
@ 480 \mathrm{kPa}(70 \mathrm{psi})\end{array}$ & $360(9)^{\mathrm{e}}$ & $182(5)^{\mathrm{e}}$ & $2448(22)^{\mathrm{e}}$ & $10,249(12)$ \\
\hline L-14780 & $52^{\mathrm{e}}$ & $7500^{\mathrm{e}}$ & $\begin{array}{c}97.6^{\mathrm{e}} 72^{\mathrm{e}} \\
(0 / 20)(0 / 70)\end{array}$ & & $\begin{array}{lr}454 * \mathrm{e} & 234 * \mathrm{e} \\
\text { @ } 1.38 \mathrm{MPa}(200 \mathrm{psi})\end{array}$ & $322(27)^{\mathrm{e}}$ & $161(15)^{\mathrm{e}}$ & $1925(20)^{\mathrm{e}}$ & $8060(11)$ \\
\hline $\begin{array}{l}\text { Vertrel } \\
\text { MCA }\end{array}$ & & & & $\begin{array}{c}0 / 20^{\mathrm{j}} \\
5 / 20^{\mathrm{k}} \\
0 / 20^{1} @ 15 \mathrm{ft}-\mathrm{lb}\end{array}$ & & $333^{\mathrm{m}}$ & $167^{\mathrm{m}}$ & $2034(6)^{\mathrm{n}}$ & $8516(3)$ \\
\hline
\end{tabular}


TABLE 3-2015 Solvent Assessment Summary Data (continued).

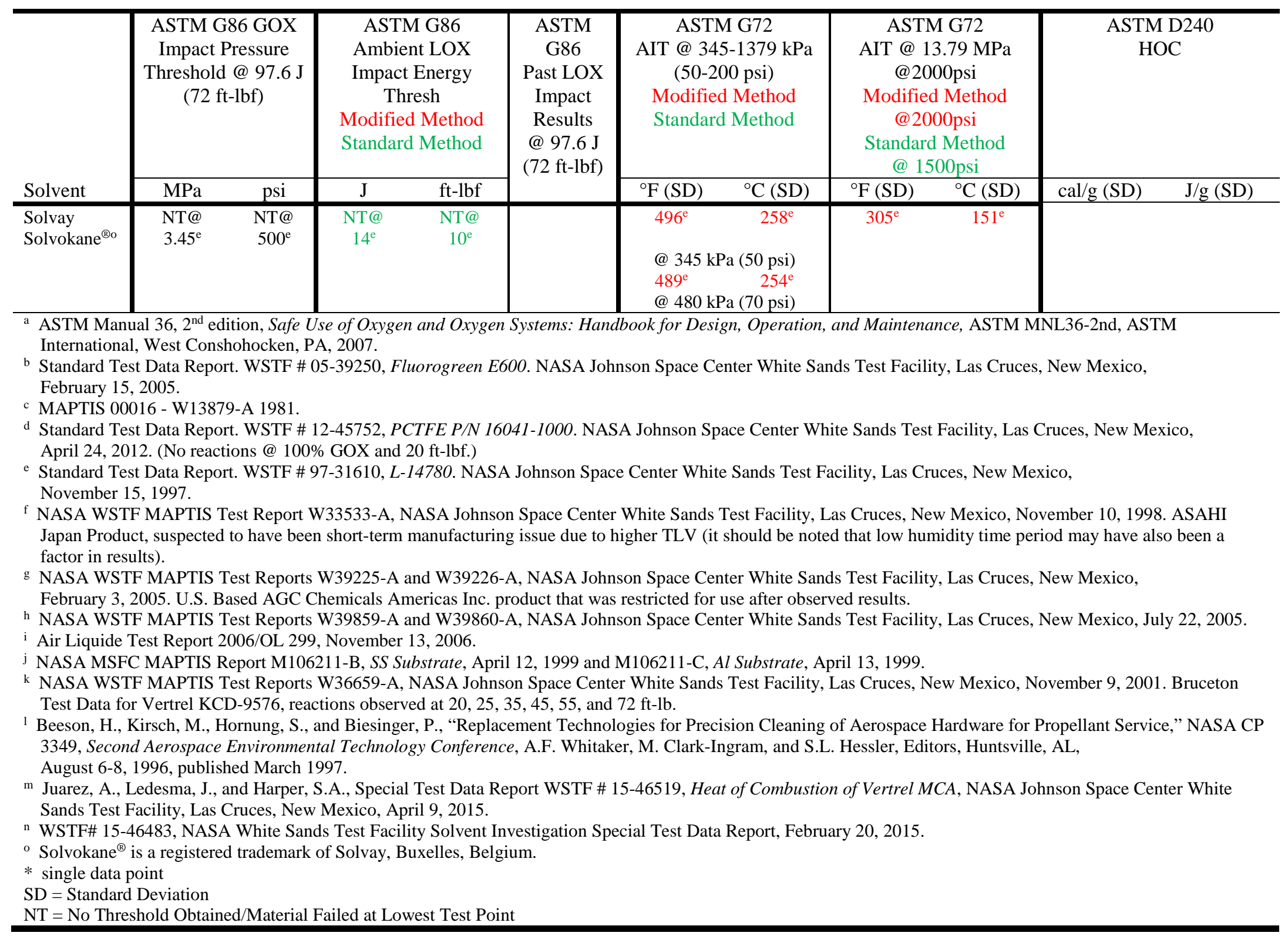




\section{Mechanical Impact Testing ASTM G86}

The ASTM G86 mechanical impact test method was used during the 2001 investigation and used again during the current study. During the 2001 study, only mechanical impact testing in LOX was performed at 97.6 J (72 ft-lbf). Non-ignition was established by obtaining zero reactions in 20 impacts or one reaction in 60 impacts at the highest energy level of $97.6 \mathrm{~J}$ (72 ft-lbf). Because of the pass/fail nature of this test, material ranking could not be performed.

An energy threshold variation of the ambient LOX test method was recommended for the current study. In energy threshold ambient LOX impact testing, if a material does not pass with either zero reactions in 20 impacts or with one reaction in 60 impacts, then impact energy is decreased until an energy level at which zero reactions are obtained in 20 impacts is reached. The passing energy threshold can then be used for ranking of materials with respect to ease of ignition. In addition to energy threshold ambient LOX impact testing, pressure threshold GOX impact testing was also recommended for this test series. This test is similar to energy threshold testing except that plummet energy level is maintained constant at $97.6 \mathrm{~J} \mathrm{(72} \mathrm{ft-lbf)} \mathrm{while} \mathrm{gas} \mathrm{pressure} \mathrm{is} \mathrm{decreased} \mathrm{until} \mathrm{a} \mathrm{pressure} \mathrm{with} \mathrm{zero} \mathrm{reactions} \mathrm{in}$ 20 impacts is reached. The passing pressure threshold can then be used for ranking of materials with respect to ease of ignition. With respect to modeling and ignition mechanism, mechanical impact testing models the impacts that may be seen during various types of valve closures. In a system, for LOX impact to occur, liquid solvent would have to be unintentionally left in the line and pooled. Gaseous oxygen impact testing would be a realistic ignition mechanism in gaseous systems with similar valve closures. In general, however, high impact energies are not frequently found in oxygen systems.

Despite its lower precision, LOX impact testing provides insight into the material's ignition sensitivity. During testing, ambient LOX impact data variability was extensively investigated. Method modifications were implemented to help reduce variability in test data [5]. Due to high volatility of solvents in question, special preparation requiring freezing of material was performed prior to testing. Freezing ensured sufficient material was retained for testing [5]. Resulting data from modified energy 
threshold ambient LOX impact testing as well standard pressure threshold GOX impact testing are presented in Table 2.

It should be noted that all candidate solvents ignited at sufficiently high pressures during pressure threshold GOX impact testing and during the original unmodified energy threshold LOX impact test method. This reinforces the finding that all solvents will ignite under certain circumstances. The AK-225G reference solvent was not tested for pressure threshold GOX impact testing and did not have any ignitions even in original unmodified energy threshold LOX impact testing.

In summary, ease of ignition was evaluated using four tests, all of which produced data that allowed ranking of materials for optimal selection: AIT G72 Low Pressure, AIT G72 High Pressure, LOX Impact G86 Energy Threshold, and GOX Impact G86 Pressure Threshold. Methods used to aid understanding ease of material ignition are shown in Fig. 1.

\section{EVALUATION OF PROPAGATION AND DAMAGE POTENTIAL}

After material ignition occurs, sustained burning and propagation to other materials may progress or it may cease. Many factors affect whether a fire will result in sustained burning including heat transfer, the geometry of the materials in question, environmental conditions, and available oxidizer. Further factors affect whether a fire will propagate and, therefore, its damage potential including amount of energy released and the initially ignited materials, heat transfer, and intimate contact with surrounding materials. A quantitative comparison of the damage potential of each of the candidate solvents was achieved by performing HOC testing per ASTM D240 [9]. Materials with higher heats of combustion have greater likelihoods of propagating fires once they themselves have been ignited. Heat of combustion is a preferred test method in that it provides a discrete data point versus pass/fail criteria for use in ranking of materials with respect to propagation and damage potential. ASTM G63-7.6.6 also provides general guidelines for evaluating a material's suitability for use in oxygen systems based on its HOC (Table 3). It 
should be noted that because of the high volatility of the solvents in question, special care had to be taken to properly seal solvent containers to ensure that sufficient material was retained for testing. ${ }^{4}$

TABLE 4-Evaluating Nonmetallic Materials for Oxygen Service (ASTM G63-7.6.6 Heat of Combustion (HOC) Evaluation Guidelines).

\begin{tabular}{lc}
\hline HOC $>10,000 \mathrm{cal} / \mathrm{g}(41.9 \mathrm{MJ} / \mathrm{kg})$ & Not recommended for use in oxygen systems \\
$2500 \mathrm{cal} / \mathrm{g}(10.5 \mathrm{MJ} / \mathrm{kg})<\mathrm{HOC}>10,000 \mathrm{cal} / \mathrm{g}$ & Caution when used in oxygen systems \\
$(41.9 \mathrm{MJ} / \mathrm{kg})$ & \\
$\mathrm{HOC}<2500 \mathrm{cal} / \mathrm{g}(10.5 \mathrm{MJ} / \mathrm{kg})$ & Preferred for use in oxygen systems \\
\hline
\end{tabular}

Only four solvents (AK-225G (as a baseline comparison solvent), Solstice PF, L-14780, and Vertrel MCA) were tested through the full battery of tests for evaluation of oxygen compatibility. The average HOC and standard deviations (SDs) are presented in Table 2. Heat of combustion data are presented as the energy output per unit mass. Though material ranking will be used for final selection, G63 evaluation guidelines provide insight. All candidate solvents fall within or on the margin of what would be considered preferred materials. Depiction of how HOC fulfills the oxygen compatibility evaluation approach is outlined in Fig. 1. It should be noted that solvents are anticipated to reside within a system's crevices in small quantities, making the damage potential small relative to most softgoods that have a long track record of safe use in oxygen systems.

\section{EVALUATION OF PROPERTIES AND CONDITIONS AFFECTING POTENTIAL RESULTS}

Any additional properties and conditions that may affect results must be taken into consideration. In the case of solvents, the impact of the material's high volatility is worth discussion.

During testing to evaluate the materials' ignitability and damage potential, the high volatility of the solvents continually posed many challenges. In AIT G72 testing, the high volatility of solvents 
complicated the ability to achieve adequate oxidizer-to-fuel ratios. Sample sizes and pressures had to be increased to achieve ignitions. In mechanical impact testing G86, the high volatility of solvents required freezing of all solvent samples to ensure sufficient material was retained for testing without evaporation [10]. In HOC D240 testing, special care had to be taken to properly seal solvent containers. This again ensured material did not evaporate and dissipate during testing. In all these cases, high volatility caused problems during testing; but this high volatility applied in a real system will work in the favor of the solvent with respect to oxygen compatibility.

Ease of Ignition - To ignite, a material must first be heated to its AIT. This increased temperature is achieved via a given ignition mechanism. Because of solvent's high volatility, the material is likely to evaporate and dissipate prior to reaching the AIT. Evaporation and dissipation quickly lead to an insufficient fuel-to-oxidizer ratio to support combustion. A solvent's extremely low surface tension additionally encourages its quick vaporization. The same phenomenon that complicated testing will help minimize the risk of ignition. When considering whether an ignited solvent will be able to transfer energy to a nearby surface and propagate, the same holds true. Once ignited, a solvent's low surface tension and volatile nature allows it and its combustion products to dissipate quickly, which makes it difficult to maintain intimate contact with surrounding materials to transfer heat energy and propagate a fire. Therefore, though solvents may have similar HOCs to many oxygen system softgoods, their propagation potential is less. In summary, the high volatility and therefore quick evaporation and dissipation of a solvent increases its oxygen compatibility because it reduces its ability to ignite, sustain combustion, and propagate fires.

\section{RANKING AGAINST PROVEN MATERIALS/SELECTION OR OPTIMAL MATERIALS}

As discussed earlier, test methods for ease of ignition and propagation potential were selected for their capability to rank materials against each other and against other proven oxygen use materials. 
Ease of ignition was evaluated using four tests, all of which produced data that allowed ranking of materials for optimal selection: AIT G72 Low Pressure, AIT G72 High Pressure, LOX Impact G86 Energy Threshold, and GOX Impact G86 Pressure Threshold. The value of using test methods that allowed ranking proved immediately effective. Across four different ranking tests, optimal and less desirable candidates became obvious. Poorer performing solvents such as Solvay Solvokane could be identified and eliminated from further testing. After completion of ignition tests, only the top ranking solvents across all four tests, such as Solstice PF and 3M L-4780, were selected to continue on to HOC damage potential testing.

Per the ASTM G63 guide and NASA-STD-6001/TM-2007-213740 approach, materials are to be selected in order of increasing resistance to ignition. The lower precision of the ASTM G86 impact energy and pressure threshold test methods makes its data ranking meaningful for identifying poor and high performers, but does not make it the optimal test for finer comparison and selection ranking. The AIT G72 low pressure ranking also assisted in the elimination of poor performing solvents. Most materials considered for use in oxygen systems are normally subjected to AIT G72 high pressure (10,300 $\mathrm{kPa}(1500 \mathrm{psi}))$ testing as part of their evaluation per the ASTM G63 guide and NASA-STD6001/TM-2007-213740. An extensive and reliable comparison AIT ASTM G72 data library is therefore available. AIT high pressure data becomes the ideal data set to use for finer ranking and optimal material selection. In this test series, AIT ASTM G72 testing was performed at 13,800 kPa (2000 psi). Nonetheless, in this high pressure range, rankings between data sets of 10,300 kPa (1500 psi) and 13,800 kPa (2000 psi) are understood to have almost identical reactivity.

If ranked for AIT alone it would be seen that all solvents, including proven AK-225G, exhibit lower AITs than what are seen for common oxygen system softgood materials. Though AK-225G does show a higher AIT of $230{ }^{\circ} \mathrm{C}\left(446{ }^{\circ} \mathrm{F}\right)$, finalist candidate solvents (Solstice PF, $182^{\circ} \mathrm{C}\left(359{ }^{\circ} \mathrm{F}\right)$; $3 \mathrm{M} \mathrm{L}-14780$, $161^{\circ} \mathrm{C}\left(322^{\circ} \mathrm{F}\right)$ ), and comparison solvent (Vertrel MCA, $\left.167^{\circ} \mathrm{C}\left(333^{\circ} \mathrm{F}\right)\right)$, do not fall far behind. Candidate solvent materials (Solstice PF and 3M L-14780) both fall within "use with care” guidelines outlined in Table $1\left(121^{\circ} \mathrm{C}<\right.$ AIT $>204^{\circ} \mathrm{C}\left(250^{\circ} \mathrm{F}<\right.$ AIT $\left.\left.>400^{\circ} \mathrm{F}\right)\right)$. The fact that final evaluated 
solvents fall within a similar range is not surprising, as these represent top performing solvents.

Furthermore, it should be noted that due to their high volatility, ignition resistance of the solvents is in fact higher than their AIT would suggest. This is validated by the fact that AK-225G has been used successfully and without incident for over a decade. Because solvent AITs depart from softgood trends, AIT was not used as the primary driver in material ranking against comparison materials.

Per the ASTM G63 guide and NASA-STD-6001/TM-2007-213740 approach, materials are to be selected in order of increasing ignition resistance and decreasing damage potential. Solvents of interest were ranked with respect to ease of ignition per ASTM G72 high pressure testing and with respect to damage potential per HOC D240 (Fig. 2). Heat of combustion was used as the primary driver in ranking of materials. For direct comparison, solvents were also ranked against proven oxygen system materials. Proven oxygen system materials are indicated in Fig. 2. Ideally the material in question will fall within this bracketed area or above it to perform successfully in oxygen systems. To illustrate the various ranges of compatibility, some marginal materials (Viton A, Nylon 6/6) and a few known poor performing materials (Buna-N, Polypropylene) were also included. Even marginal materials such as Nylon 6/6 have been used with wide success in oxygen systems. Nylon 6/6 is relatively energetic, readily burns in air, but is commonly used in oxygen regulators. The reason for its success is its end-use configuration. Despite its flammability characteristics, it is not flammable in its configuration due to the lack of ignition hazards. Both candidate solvents are less energetic per unit mass than Nylon 6/6. Arrows in Fig. 2 help indicate the preferred descending order for HOC and the preferred ascending order for AIT with respect to oxygen compatibility.

No direct correlation between energy potential and ignition susceptibility can be inferred from Fig. 2. Both candidates (L-14780 and Solstice PF) as well as currently used Vertrel MCA, ranked below AK-225G. Nonetheless, these same solvents ranked above common oxygen system materials Kel-F ${ }^{\circledR 11} /$ Neoflon ${ }^{\circledR 12}$ and Vespel SP-21. When comparing the three solvents L-14780, Solstice PF, and

11 Kel-F ${ }^{\circledR}$ is a registered trademark of M.W. Kellogg Company, Jersey City, NJ.

12 Neoflon $^{\circledR}$ is a registered trademark of Daikin Industries, LTD., Osaka, Japan. 
Vertrel MCA to each other, both HOC and AIT data are very closely grouped. The oxygen compatibility of these solvents can be considered in the same range, as it is difficult to say that any one solvent is more oxygen compatible than the other. The double arrow in Fig. 2 represents the interchangeable nature of these three solvents in their ranking against other materials.

\section{Conclusions}

The concepts behind ASTM G63 Guide and NASA-STD-6001/TM-2007-213740 approaches were used to develop an expanded logic to assess and select optimal oxygen-compatible replacement solvents beyond evaluation of non-ignitability. Fundamental evaluation areas included ease of ignition, propagation and damage potential, properties affecting potential results, and ranking of materials data against proven oxygen-compatible materials for selection of optimal performers. Test methods or test method variations were selected that allowed for performance ranking versus pass/fail results.

All solvents, including proven AK-225G, exhibit lower AITs than what are seen for common oxygen system softgood materials. Nonetheless, it should be noted that due to their high volatility, ignition resistance of the solvents is in fact higher than their AITs would suggest. This is validated by the fact that AK-225G has been used successfully and without incident for over a decade. The high volatility, and therefore quick evaporation and dissipation, of a solvent increases its oxygen compatibility as it reduces its ability to ignite, sustain combustion, and propagate fires. In addition, it should be noted that solvents are anticipated to reside within a system's crevices in small quantities, making the damage potential small relative to most softgoods that have a long track record of safe use in oxygen systems.

Ranking of all test data was used to first eliminate poor performing solvents. Candidate solvents were down-selected at many points in the investigation based on not only oxygen compatibility but also due to their performance across other selection criteria such as metals compatibility, nonmetal compatibility, cleaning effectiveness, nonvolatile residue, environmental regulation standing, user friendliness, and health. Only four solvents were tested through the full battery of tests for evaluation of oxygen 
compatibility (AK-225G as a baseline comparison, Solstice PF, L-14780, and Vertrel MCA). For final selection placement, front-runner solvents were ranked with respect to ease of ignition per ASTM G72 high pressure testing and with respect to damage potential per HOC D240. Due to their high volatility, solvents exhibit higher resistance to ignition than their ASTM G72 AIT data would suggest. As a result, HOC was used as a primary driver for ranking in order of decreasing damage potential. Baseline solvent AK-225G exhibited the lowest HOC and highest AIT of solvents tested. Nonetheless, Solstice PF, L-14780, and Vertrel MCA heats of combustion all fell well within the range of properties that are associated with proven oxygen system materials. Tested AITs for these solvents fell only slightly lower than the AIT for the proven AK-225G solvent. Based on these comparisons in which solvents exhibited properties within those ranges seen with proven oxygen system materials, it is believed that Solstice PF, L-14780, and Vertrel MCA would perform well with respect to oxygen compatibility. From these solvents, final selection of a solvent can be based on other performance factors.

\section{References}

[1] Goldberg, J.S., Delgado, R., Biesinger, P., Hornung, S.D., and Beeson, H.D., United States Air Force Wipe Solvent Testing, Investigative Report WSTF-IR-0134-002-01, NASA Johnson Space Center White Sands Test Facility, Las Cruces, NM, September 18, 2001.

[2] Burns, H.D., Mitchell, M.A., and McMillian, J.H., Farner, B.R., Harper, S.A., Peralta, S.F., Lowrey, N.M., Ross, H.R., and Juarez, A., Replacement of Hydrochlorofluorocarbon-225 Solvent for Cleaning and Verification Sampling, of NASA Propulsion Oxygen Systems Hardware, Ground Support Equipment, and Associated Test Systems. NASA Technical Publication NASA/TP-2015218207, Marshall Space Flight Center, Huntsville, AL, 2015.

[3] ASTM G72/G72M-09, Standard Test Method for Autogenous Ignition Temperature of Liquids and Solids in a High-Pressure Oxygen-Enriched Environment, ASTM International, West Conshohocken, PA, 2009, DOI:10.1520/C0033-03, www.astm.org. 
[4] ASTM G86-98a, “Standard Test Method for Determining Ignition Sensitivity of Materials to Mechanical Impact in Ambient Liquid Oxygen and Pressurized Liquid and Gaseous Oxygen Environments,” ASTM International, West Conshohocken, PA, 1998 (R 2011), DOI:10.1520/C0033-03, www.astm.org.

[5] Juarez, A., Ledesma, J., and Harper, S.A, Solvent Investigation, Special Test Data Report WSTF\# 15-46483, NASA Johnson Space Center White Sands Test Facility, Las Cruces, NM, 2015.

[6] ASTM G63-99, Standard Guide for Evaluating Nonmetallic Materials for Oxygen Service, ASTM International, West Conshohocken, PA, 1999 (R 2007), DOI: 10.1520/C0033-03, www.astm.org.

[7] NASA-STD-6001B, Flammability, Offgassing, and Compatibility Requirements and Test Procedures, Test 1, Upward Flame Propagation, National Aeronautics and Space Administration, Washington, DC, August 2011.

[8] Rosales, K.R., Shoffstall, M.S, Stoltzfus, J.M., Guide for Oxygen Compatibility Assessments on Oxygen Components and Systems, NASA Technical Memorandum NASA/TM-2007-213740. NASA Johnson Space Center White Sands Test Facility, Las Cruces, NM, 2007.

[9] ASTM D240-14, Standard Test Method for Heat of Combustion of Liquid Hydrocarbon Fuels by Bomb Calorimeter, ASTM International, West Conshohocken, PA, 2014, DOI: 10.1520/C0033-03, www.astm.org.

[10] Juarez, A., Harper, S.A., “Improved ASTM G72 Test Method for Ensuring Adequate Fuel to Oxidizer Ratios,” Fourteenth International Symposium on Flammability and Sensitivity of Materials in Oxygen-Enriched Atmospheres, STP 1596, E. Davis and T.A. Steinberg, Editors, STP-2015-0080, ASTM International, West Conshohocken, PA, 2016 publication in process. 


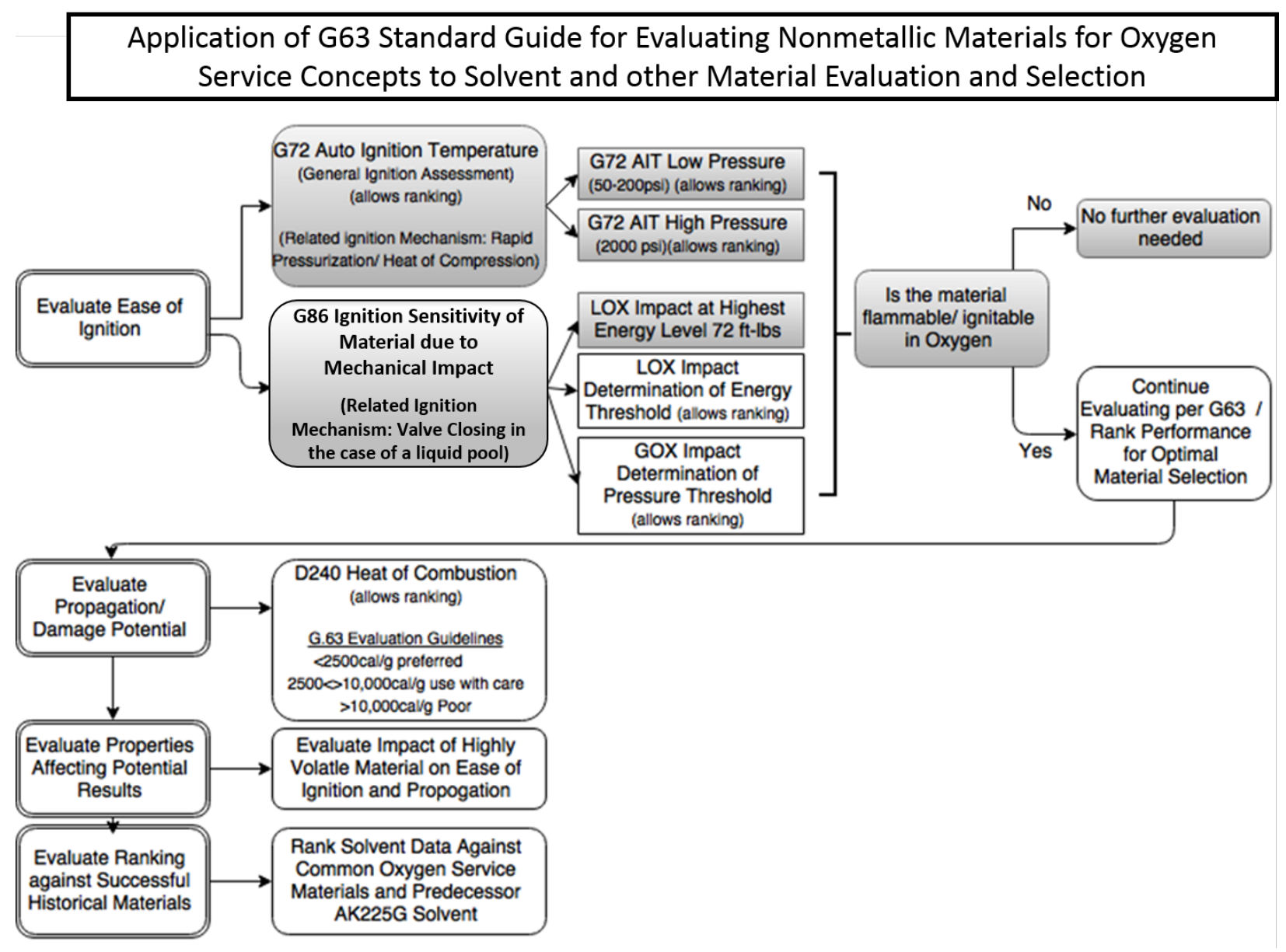

FIG. 1: 2015 Solvent Investigation Oxygen Compatibility Evaluation and Selection Methodology - Application of Concepts from

G63 (2001 Solvent Investigation and Selection Methodology Highlighted in Grey).

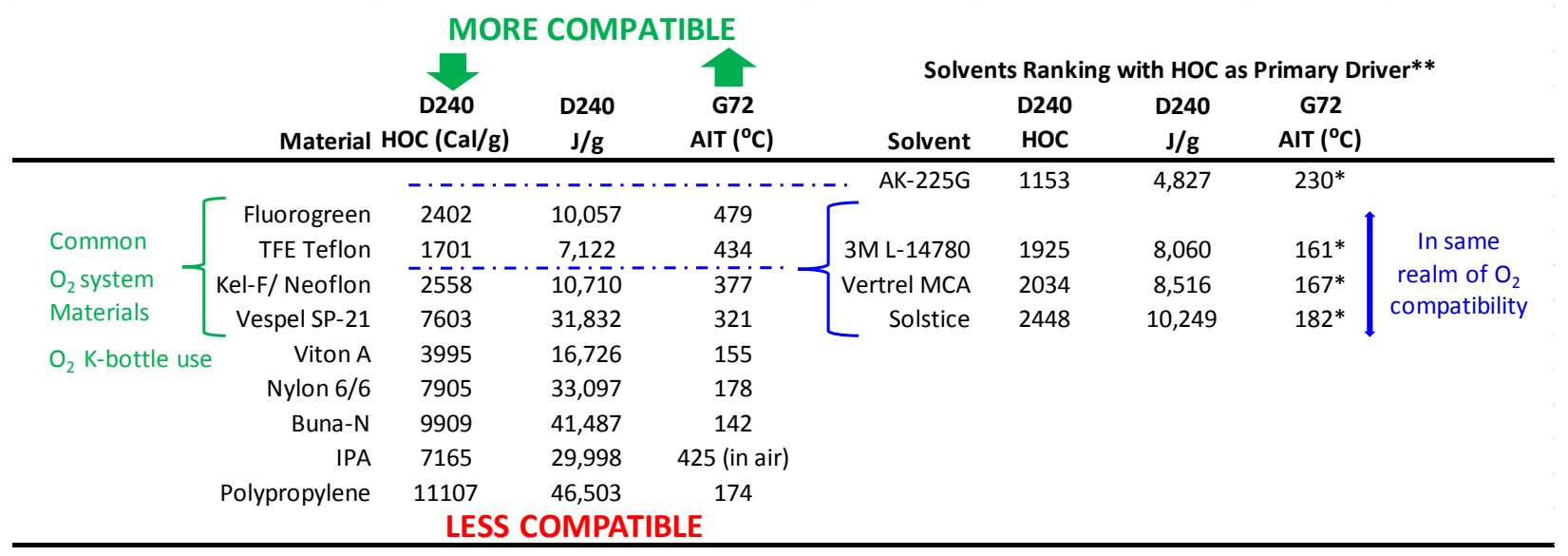

*AIT method performed at 13,800 kPa (2000 psi) Oxygen (Standard method performed at 10,300 kPa (1500 psi)

**Volatile solvents are ranked with HOC as a primary driver. Due to their high volatility, ignition resistance performance of solvents is in fact higher than their AIT would suggest.

FIG. 2: Solvent Ranking against Proven Oxygen System Materials and Known Poor Performers for Oxygen Compatibility. 